\title{
The Effect of Atrial Pacing-Induced Tachycardia on Left Ventricular Contractile Function in Conscious Newborn and Adult Sheep
}

\author{
DAVID J. FISHER ${ }^{(42)}$ AND DONALD M. GROSS \\ Department of Pediatrics of The University of Texas Medical School at Houston, Houston, Texas, USA
}

\begin{abstract}
Summary
In order to determine if an increase in heart rate is associated with an increase of left ventricular contractile function during the neonatal period we recorded phasic and mean aortic blood pressure, left atrial mean or left ventricular end diastolic pressure, phasic left ventricular blood pressure, aortic blood flow velocity and the instantaneous first derivatives of left ventricular blood pressure $(\mathrm{dP} / \mathrm{dt})$ and aortic blood flow velocity $(\mathrm{dV} / \mathrm{dt})$ during pacing-induced tachycardia in conscious newborn and adult sheep. There was a significant positive linear correlation between heart rate and both indices of contractility $(\mathrm{dP} / \mathrm{dt}$ and $\mathrm{dV} / \mathrm{dt}$ ) in both age groups. Left ventricular end diastolic pressure was unchanged except for a decrease at the most rapid heart rate in the newborns. There was no change in aortic mean blood pressure during the study. Our data demonstrate that an increase of heart rate is associated with an increase of left ventricular contractile function in conscious neonatal and adult sheep. Investigations of the effects of potential inotropic agents on left ventricular contractile performance in newborns and adults must evaluate the independent effect of any simultaneously occurring increase in heart rate.
\end{abstract}

The positive inotropic effect of an increase of contraction frequency was originally demonstrated in vitro by Bowditch (5). Multiple recent investigations in vitro have demonstrated that atrial pacing-induced tachycardia is associated with a small but significant increase in left ventricular contractile function in conscious adult humans and dogs $(9,17-19,28,33)$. Although there is some information available concerning the effect of a heart rate increase on left ventricular contractility in the unanesthetized lamb fetus $(1,23)$ and in neonatal cat and lamb heart muscle in vitro $(1,8)$, to our knowledge there is no such information available in conscious neonates of any species. Therefore, we studied the effect of a pacing-induced heart rate increase on left ventricular contractile function in conscious newborn lambs. As species variability has been reported in adults (25) we also performed a pacing study in conscious adult sheep.

\section{MATERIALS AND METHODS}

Surgical technique. We operated on 11 Western newborn lambs $1-25(9 \pm 2$, mean \pm S.E. $)$ days after birth and on 8 nulliparous female adult sheep. The lambs weighed $6.5 \pm 0.6 \mathrm{~g}$. We anesthetized the animals with 1-2\% fluothane (Halothane), intubated the trachea, and ventilated the lungs with an animal ventilator (Methomatic, Pittman-Moore). We performed a thoracotomy in the left fourth intercostal space and inserted polyvinyl catheters (inside diameter, $0.10 \mathrm{~cm}$; outside diameter, $0.15 \mathrm{~cm}$ ) into the ascending aorta via the left internal thoracic artery and into the left atrium through a purse-string suture in the atrial appendage. The catheters were closed after they were filled with heparin. We sutured a pair of stainless steel pacing wires (\#A5633 hookup wire, Cooner Wire Co., Chatsworth, CA) to the left atrial epicardium. Through a separate incision in the left neck we isolated the left carotid artery and introduced a solid state pressure/velocity catheter (\#VPC 663A, Millar Instruments, Inc., Houston, TX). During continuous monitoring of blood pressure and flow velocity the catheter was advanced retrograde across the aortic valve and positioned so that the pressure transducer (located at the catheter tip) and the fluid velocity sensor (located $3 \mathrm{~cm}$ from the catheter tip) were located within the left ventricle and the proximal ascending aorta, respectively (29). Two electrocardiographic leads were sutured to the left chest after closure of the ribs.

We sutured the wounds, tunnelled the catheters and wires to the left exterior chest and protected them with a nylon mesh animal jacet (Alice King Chatam, Los Angeles, CA). Antibiotics were given as described previously $(13$,$) .$

As described previously (13), on each postoperative day the lambs were blindfolded and placed in a canvas sling located in the well-isolated study room. The polyvinyl catheters were drained of the heparin, flushed with $2 \mathrm{ml}$ of normal saline, filled with fresh heparin and closed. This conditioning to environment and investigator movement resulted in quiet lamb and stable variables during the study period.

Experimental protocol. The lambs were allowed to feed from their mother until $1 \mathrm{~h}$ before study. At that time they were placed in a canvas sling and we began a continuous slow recording of a precordial electrocardiogram, phasic pressure in the aorta and left ventricle, mean pressure in the left atrium or end diastolic pressure in the left ventricle, and the instantaneous first derivatives of left ventricular pressure $(\mathrm{dP} / \mathrm{dt})$ and aortic blood velocity $(\mathrm{dV} / \mathrm{dt})$. Mean aortic blood pressure was recorded intermittently from the phasic signal. The adult sheep were studied in a similar fashion while standing in a metabolic cage.

Preliminary studies indicated that atrioventricular block with irregular rhythm ocurred at $280-320$ beats per min (bpm) in the newborns and 180-220 bpm in the adults. In order to study the effects of tachycardia on contractile function but also to avoid heart block, after the the control measurements had been recorded at 25 and $100 \mathrm{~mm}$ per sec the heart rate was increased by pacing the left atrium and the measurements were repeated at approximately 240 and $300 \mathrm{bpm}$ in the newborns, and 140 and $180 \mathrm{bpm}$ in the adults. Arterial $\mathrm{PO}_{2}, \mathrm{PCO}_{2}$, and $\mathrm{pH}$ were measured once in each animal, after the above data was recorded.

A single study was performed on each newborn and 1-2 studies were performed on each adult. Serial studies in adult sheep were seperated by 2 days. As paired $t$ testing showed no significant difference between the first and second studies in adults, the results were pooled (40). A total of 11 studies were performed in the newborns and 15 studies were performed in the adults. Each study was performed 2, 3, or 4 days after surgery. It is recognized that a longer period of time between the surgery and the study may have allowed a more complete recovery, but a shorter period was chosen in order to study the newborns in the conscious state as soon as possible after birth. All the newborn sheep were fully conscious, ambulatory, and vigorously feeding from their ewe by the day after surgery.

Measurements and calculations. Aortic and left atrial pressures 
were measured with Statham P23Db transducers referenced to atmospheric pressure with zero obtained at the mid-chest position. The left ventricular pressure transducer was calibrated by matching the left ventricular end diastolic pressure with the left atrial mean pressure, and the peak systolic pressure in the left ventricle and aorta. Aortic blood flow velocity was measured with a Narco RT400 flowmeter. Mechanical zero was the flat portion of the tracing, which occurs in late diastole. The gain of the velocity catheter was calibrated with an in vitro hydraulic system. As the velocity profile of blood flow across the ascending aorta is flat (12) movement of the velocity probe within the cross section of the aorta during the study should not change the output signal. We measured $\mathrm{dP} / \mathrm{dt}$ and $\mathrm{dV} / \mathrm{dt}$ with a single Beckman 9879 differentiating by connecting the left ventricular pressure and aortic blood flow velocity signals to the differentiator through a double pole, double throw switch box. The differentiating circuit is calibrated with a $3.18 \mathrm{~Hz}$ internal sine wave and produces an output which is linear to $100 \mathrm{~Hz}$. A precordial electrocardiogram was recorded with a Beckman 9855 coupler. The heart rate was measured directly from the rapid speed tracings, which were recorded during the control and pacing periods. All of the signals were recorded on a Beckman R-611 direct writing recorder.

Arterial $\mathrm{PO}_{2}, \mathrm{PCO}_{2}$, and $\mathrm{pH}$ were measured with a blood gas analyzer (Instrumentation Laboratories 713) and appropriate electrodes. Hemoglobin concentration was measured with a Hemoximeter OSM2 (Radiometer, Copenhagen, Denmark). A total of 0.5 $\mathrm{ml}$ of blood was used for each set of measurements.

We calculated the mean \pm standard error for each variable during the control period and the 2 pacing periods for the newborn and adult sheep (40). We examined for within group changes by analysis of variance (39). When the computed $F$ ratio exceeded the critical F ratio (at $P=0.05$ ), Dunnett's test was used to identify the group(s) that were significantly different (39). As there is only one point of similar heart rate $(190 \mathrm{bpm})$ between the newborns and adults, it is not possible to examine for between group variability with statistical testing. $T$ testing and linear regression analysis was used where appropriate $(39,40)$.

\section{RESULTS}

The systemic arterial blood gases, $\mathrm{pH}$, and hemoglobin concentration (Table 1) for the newborn and adult sheep were within

Table 1. Arterial blood $\mathrm{PO}_{2}, \mathrm{PCO}_{2}$, and $\mathrm{pH}$ in newborn and adult sheep ${ }^{1}$

\begin{tabular}{lcc}
\hline & Newborns & Adults \\
\hline $\mathrm{PO}_{2}$ (torr) & $81 \pm 2$ & $91 \pm 2^{2}$ \\
$\mathrm{PCO}_{2}$ (torr) & $40 \pm 2$ & $36 \pm 1$ \\
$\mathrm{pH}$ (units) & $7.41 \pm 0.02$ & $7.44 \pm 0.01$ \\
Hemoglobin (g/dl) & $10.6 \pm 0.5$ & $11.2 \pm 0.5$ \\
\hline \multicolumn{1}{l}{${ }^{1}$ Values ar given }
\end{tabular}

${ }^{1}$ Values are given as mean \pm S.E. Newborn lambs, $n=11$; adult sheep,

$n=15$. Variables were compared with an unpaired $t$ test (40).

${ }^{2} P<0.05$ normal limits that have been published previously $(3,13,14)$. The arterial oxygen tension was greater in the adults and the other variables were similar in the two groups (Table 1).

During the control period, peak systolic and end diastolic pressure in the left ventricle and mean aortic blood pressure were significantly lower in the newborn lambs than in the adult sheep (Table 2). Heart rate was significantly greater in the newborns during the control period. All of these values are within the normal limits that have been published previously for conscious newborn and adult sheep $(3,13,24)$. During the most rapid heart rate there was a small but significant decrease in left ventricular end diastolic pressure in the newborns (Table 2), but no significant change in the adults. Aortic mean blood pressure and peak systolic left ventricular pressure did not change in the newborn or adult sheep during the tachycardia. Tracings representative of the effects of pacing-induced tachycardia on the variables that were studied are shown for a newborn and an adult in Figure 1 and 2, respectively. There was a significant positive linear increase in $\mathrm{dP} / \mathrm{dt}$ and $\mathrm{dV} / \mathrm{dt}$ during the tachycardia in the newborn and adult sheep (Fig. 3 and 4).

All animals were studied during 1:1 atrioventricular conduction. The maximal heart rate achieved before some degree of heart block (with irregular dropped ventricular complexes) occurred was $290-315$ in the newborns and $175-205$ in the adults.

\section{DISCUSSION}

As myocardial fiber shortening (performance) varies directly with changes of preload and inversely with afterload (6) a change in left ventricular contractile performance is most simply demonstrated when myocardial fiber shortening changes and loading conditions remain constant (35). Although it is possible to closely control loading conditions and make precise measurements of inotropic change in vitro, loading conditions may vary considerably during an investigation of a potential inotropic intervention in conscious subjects. Consequently, there has been a great deal of investigation focused upon developing a highly sensitive index of contractility, which may be measured in vivo but remains insensitive to changes in cardiac loading conditions. In general, it has been determined that the isovolumic phase indices of contractility vary directly with changes of preload and ejection phase indices of contractility vary inversely with changes in afterload (27). The directly measured maximal positive first derivatives of left ventricular pressure and aortic blood flow velocity provide excellent sensitivity to changes in contractile performance but also are significantly affected by alterations of preload and afterload, respectively $(30,38)$. Other isovolumic and ejection phase indices of contractility, such as $\mathrm{dP} / \mathrm{dt}$ at a developed pressure of 40 $\mathrm{mmHg}$, the velocity of the contractile element and the velocity of circumferential fiber shortening may offer some insensitivity to alterations of loading conditions, but they provide no greater sensitivity to changes in contractility (27). After considering that previous observations in conscious adult dogs and humans demonstrated that pacing-induced tachycardia was associated with

Table 2. Heart rate, aortic mean blood pressure, and phasic left ventricularpressure in conscious newborn and adult sheep ${ }^{1}$

\begin{tabular}{|c|c|c|c|c|c|c|}
\hline \multirow[b]{3}{*}{ Heart rate/min } & \multicolumn{3}{|c|}{ Newborns } & \multicolumn{3}{|c|}{ Adults } \\
\hline & \multirow{2}{*}{$\frac{\text { Control }}{191 \pm 2}$} & \multicolumn{2}{|c|}{ Pacing } & \multirow{2}{*}{$\frac{\text { Control }}{76 \pm 3}$} & \multicolumn{2}{|c|}{ Pacing } \\
\hline & & $241 \pm 9^{2}$ & $301 \pm 5^{2}$ & & $140 \pm 7^{2}$ & $185 \pm 13^{2}$ \\
\hline $\begin{array}{l}\text { Aortic mean blood pres- } \\
\text { sure (mmHg) }\end{array}$ & $68 \pm 1$ & $68 \pm 3$ & $69 \pm 3$ & $88 \pm 2$ & $89 \pm 3$ & $86 \pm 2$ \\
\hline $\begin{array}{l}\mathrm{LV}^{3} \text { systolic pressure } \\
\quad(\mathrm{mmHg})\end{array}$ & $80 \pm 3$ & $80 \pm 5$ & $81 \pm 4$ & $105 \pm 3$ & $110 \pm 5$ & $106 \pm 5$ \\
\hline $\begin{array}{l}\text { LV end diastolic pressure } \\
(\mathrm{mmHg})\end{array}$ & $3.2 \pm 0.4$ & $3.0 \pm 0.5$ & $2.2 \pm 0.2^{2}$ & $5.5 \pm 0.3$ & $5.3 \pm 0.3$ & $5.2 \pm 0.4$ \\
\hline
\end{tabular}

\footnotetext{
${ }^{1}$ Values are mean \pm S.E. $n=11$ newborns and 15 adults.

${ }^{2}$ Significantly $(P<0.05)$ different from its control value, using analysis of variance with Dunnett's test (39). All adult and newborn control values are significantly $(P<0.05)$ different, using an unpaired $t$ test $(40)$.
}

${ }^{3} \mathrm{LV}$, left ventricular. 
ECG
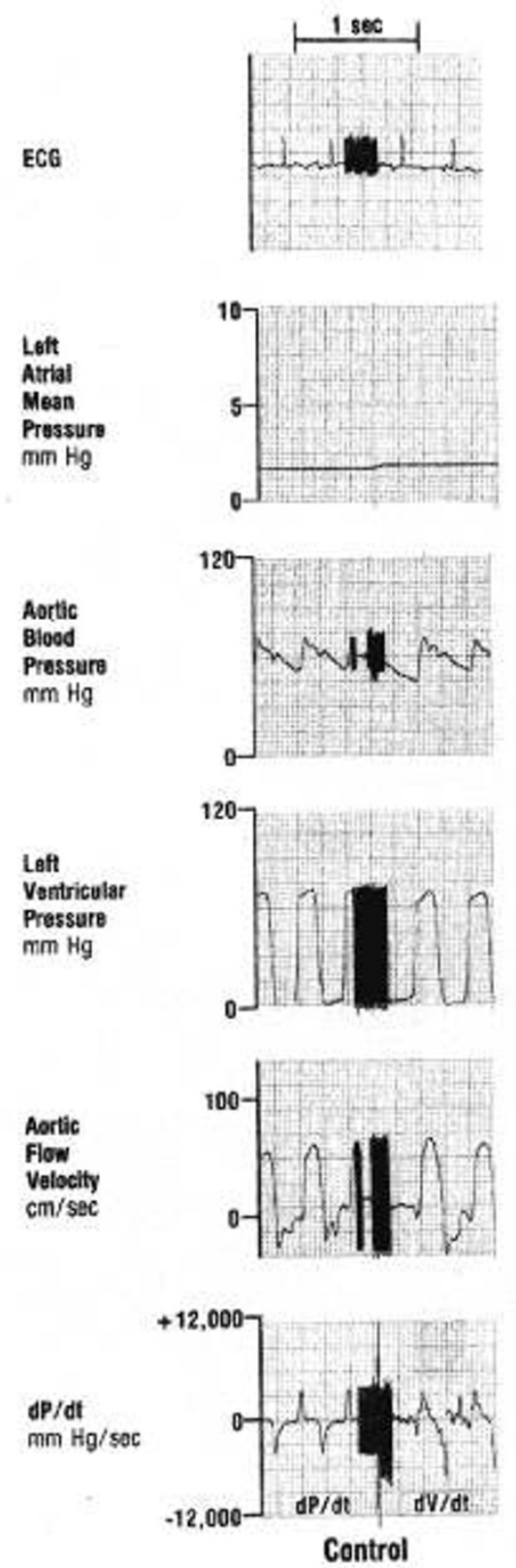
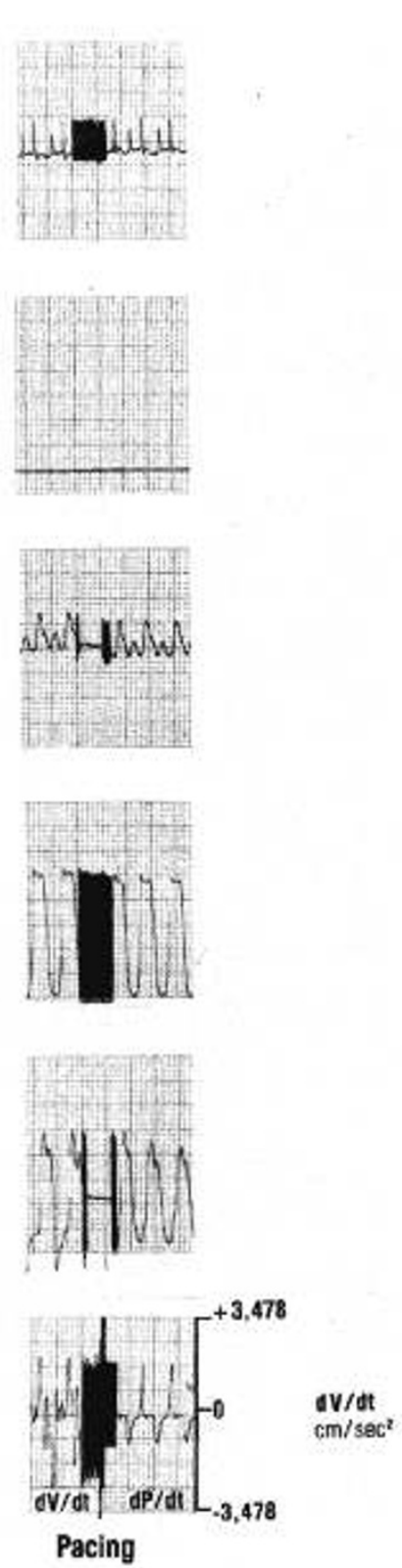

Fig. 1. Representative recordings from the conscious 7-day-old lamb of a precordial electrocardiogram (ECG), left atrial mean pressure, phasic and mean aortic blood pressure, phasic left ventricular blood pressure, ascending aortic blood flow velocity and the first derivatives of left ventricular blood pressure $(\mathrm{dP} / \mathrm{dt})$ and aortic blood velocity $(\mathrm{dV} / \mathrm{dt})$. The left column was recorded during the control period when the heart rate was 150 bpm and the right column was recorded during a period of pacing induced tachycardia when the heart rate was $270 \mathrm{bpm}$.

either a decreased or constant preload and an increased or constant afterload we used the directly measured maximal positive $\mathrm{dP} / \mathrm{dt}$ and $\mathrm{dV} / \mathrm{dt}$ to estimate the contractile function of the left ventricle during the study $(2,9,18,19,21,27)$. A decrease in preload (Table 2) would be expected to minimize the magnitude of an increase in $\mathrm{dP} / \mathrm{dt}$ and have no significant effect on $\mathrm{dV} / \mathrm{dt}$ whereas an increase in afterload would minimize the magnitude of an increase in $\mathrm{dV} /$ $\mathrm{dt}$ and have no significant effect on $\mathrm{dP} / \mathrm{dt}(30,38)$.

Cardiac output represents the combined effect of its four determinants: preload, afterload, contractility, and heart rate (6). As birth is associated with significant alterations of these determinants (36) and a doubling of cardiac output (26), there is significant interest and information available regarding the effects of isolated alterations of the determinants of cardiac output on cardiac function and output during the perinatal period. Most of the available information is focused on alterations of preload: studies on unanesthetized fetal and neonatal lambs have shown that an increase of preload is associated with an increase of stroke volume and cardiac output $(10,15,22,24)$. The increase of pulmonary blood flow that occurs after the onset of respiration should increase left ventricular preload and this may account for some of the increase of cardiac output which occurs at birth. The removal of the low resistance placental circulation at birth may be associated with an increase in the afterload against which the left ventricle must work. As stroke volume decreases during an increase of afterload in the neonatal lamb (10), a postnatal increase in left ventricular afterload would not appear to contribute toward the increase of cardiac output which occurs after birth. Left ventricular contractile function appears to increase postnatally and this should contribute significantly to the postnatal rise of cardiac output $(3,34)$. Heart rate is approximately $30 \%$ greater in newborn than in fetal lambs $(3,13,14,25)$. The data from the present study (Fig. 3 and 4$)$ and others $(1,8)$ would suggest that some of the postnatal increase of contractile function and cardiac output may occur as a result of the inotropic effect of an increase in heart rate; however, the magnitude of the increase in contractile function, which occurs 

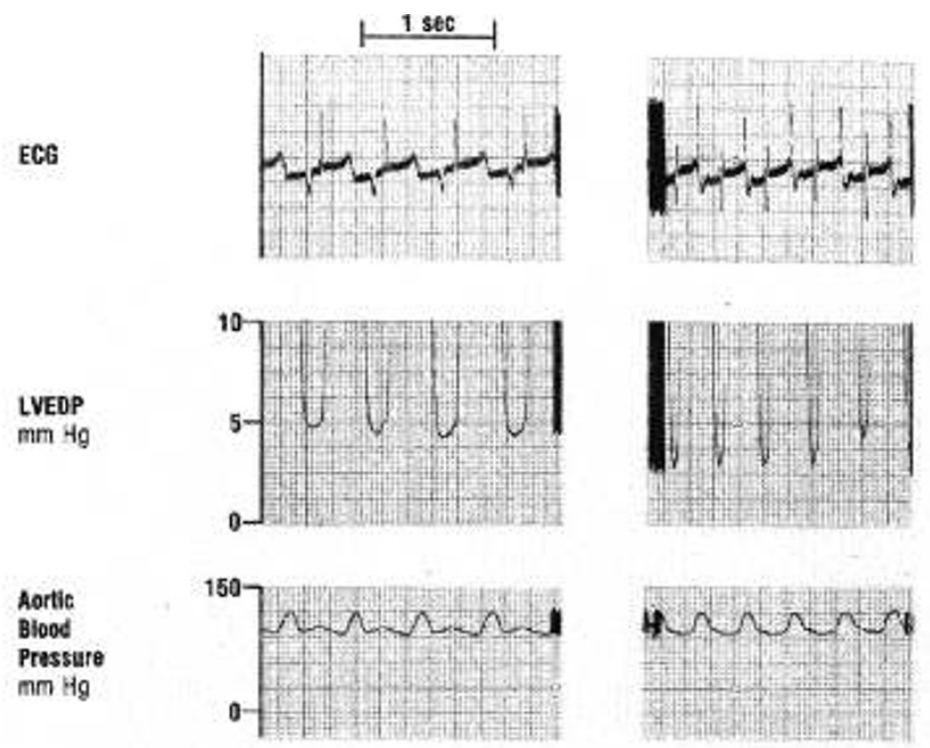

\section{Left \\ Yentricular \\ Pressure \\ $\mathrm{mm} \mathrm{Hg}$}
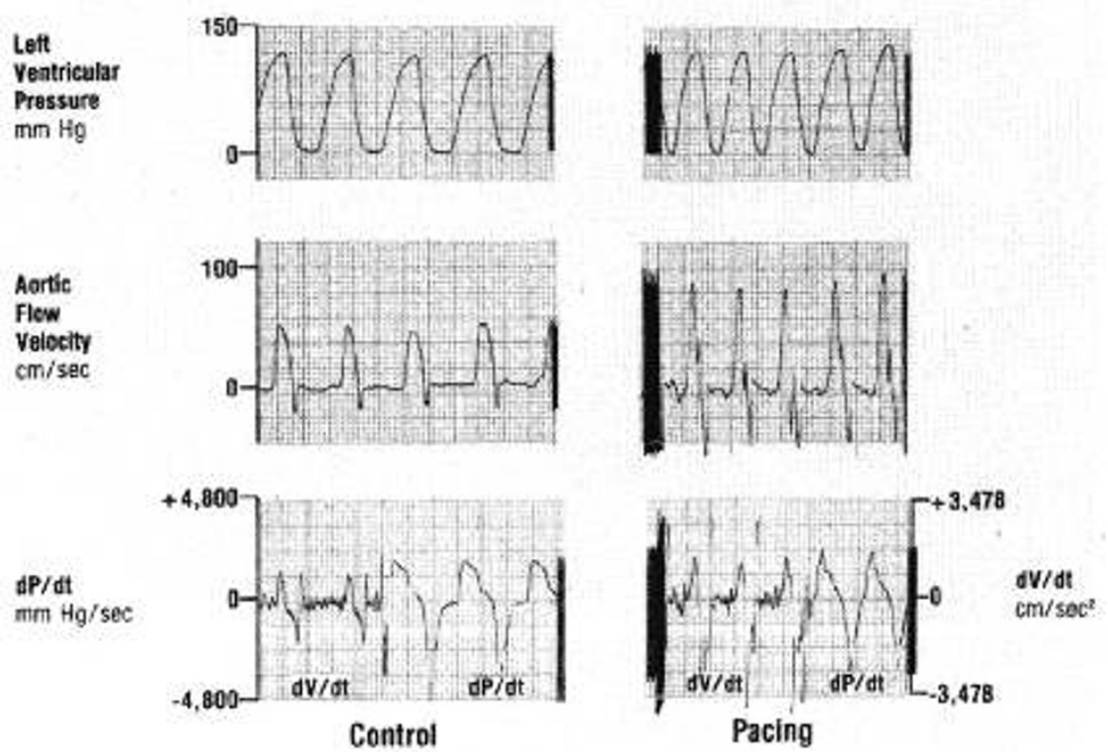

Fig. 2. Representative recordings from a conscious, nulliparous adult sheep of a precordial electrocardiogram (ECG), left ventricular end diastolic pressure (LVEDP), phasic and mean aortic blood pressure, phasic left ventricular blood pressure, ascending aortic blood flow velocity and the first derivatives of left ventricular blood pressure $(\mathrm{dP} / \mathrm{dt})$ and aortic blood velocity $(\mathrm{dV} / \mathrm{dt})$. The left column was recorded during the control period when the heart rate was $105 \mathrm{bpm}$ and the right column was recorded during a period of pacing induced tachycardia when the heart rate was $155 \mathrm{bpm}$. The direction of the ECG signal was changed during the pacing period in order to clearly demonstrate the pacing spike.

postnatally $(3,34)$, may be greater than that which could be accounted for from the inotropic effect of the heart rate increase alone (Fig. 3 and 4). Consequently, it appears that there may also be other factors that contribute to the postnatal increase in left ventricular contractile performance. It is also noteworthy that moderately severe arterial hypoxemia is associated with an increase of both heart rate and cardiac output in the newborn lamb (37). In this regard, some of the increase in cardiac output which occurs during arterial hypoxemia may be the result of an inotropic effect of the associated increase of heart rate.

The positive inotropic effect of pacing-induced tachycardia has been demonstrated previously in unanesthetized lamb fetuses and in neonatal cat and lamb myocardial muscle strips in vitro $(1,8$, 23). The current study provides further developmental evidence of an increase of left ventricular contractile function during tachycardia during the neonatal period (Fig. 3 and 4). Over a similar range of heart rates the positive inotropic effect of tachycardia would appear to be greater in the neonatal lamb than in the fetus
(23). In contrast to the lamb fetus (23), we found no decrease in contractile performance beyond a heart rate of 270 beats per min. Although Kirkpatrick and associates (23) found greater sensitivity to tachycardia in the pre-ejection phase index $(\mathrm{dP} / \mathrm{dt})$ than in the ejection phase indices that were studied, we found nearly equal sensitivity for indices of both phases (Fig. 3 and 4). This suggests that the maximal positive derivative of aortic blood flow velocity may be more sensitive than other ejection phase indices, such as mean circumferential fiber shortening to a frequency-induced change of left ventricular contractile function.

Anderson and associates (1) have demonstrated previously the positive inotropic effect of tachycardia in sheep from 0.6 of gestation through adulthood. We also found a significant increase of left ventricular contractile function during tachycardia in the adult sheep (Fig. 3 and 4). Because the magnitude of the positive inotropic effect of tachycardia depends on the basic heart rate (1) and as there was no range of overlap for the heart rates between the newborn and adult sheep it is not possible to compare the two 


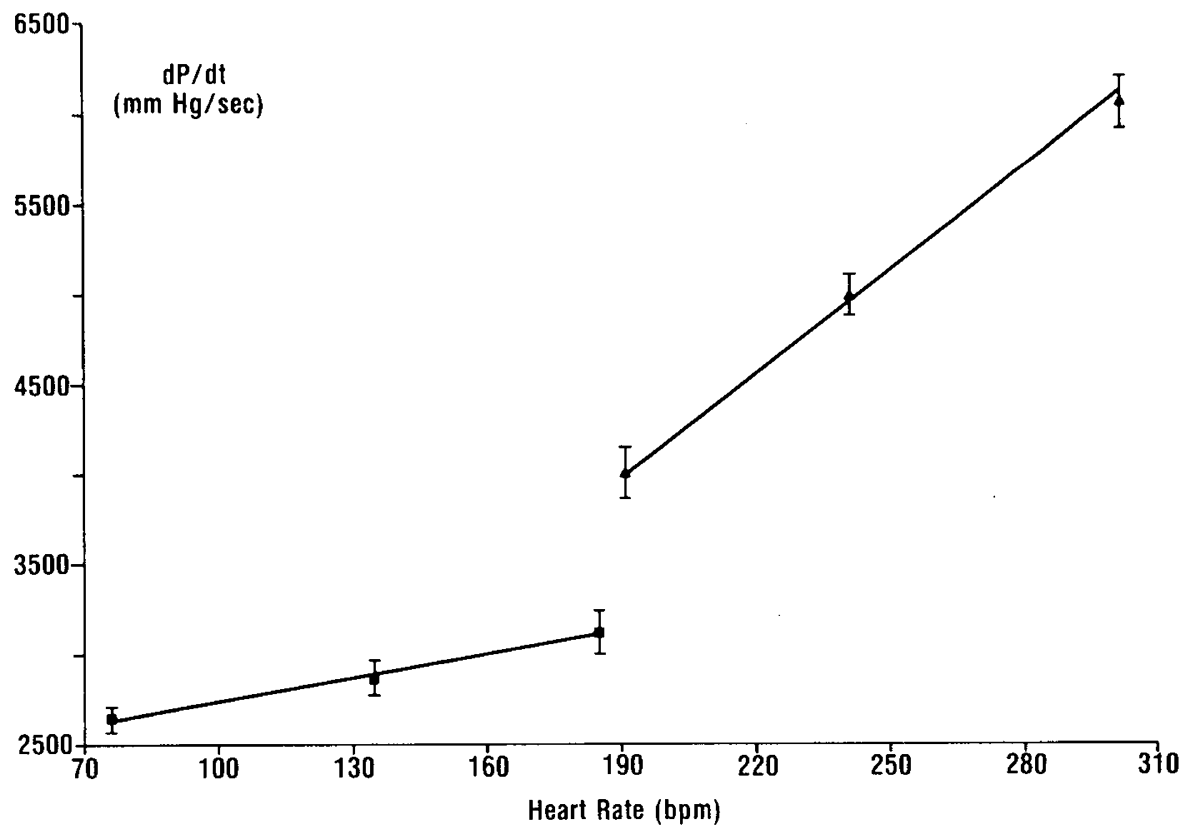

Fig. 3. The effect of pacing induced tachycardia on $\mathrm{dP} / \mathrm{dt}$. For the adults $(\square)$, the relationship is described by $\mathrm{y}=4.4 \mathrm{x}+2289 ; r=0.98$. For the newborns $(\mathbf{A})$, the relationship is described by $\mathrm{y}=18.7 \mathrm{x}+443 ; r=0.98$. Values are given as mean \pm S.E. The standard errors of the heart rates are given in Table 2.

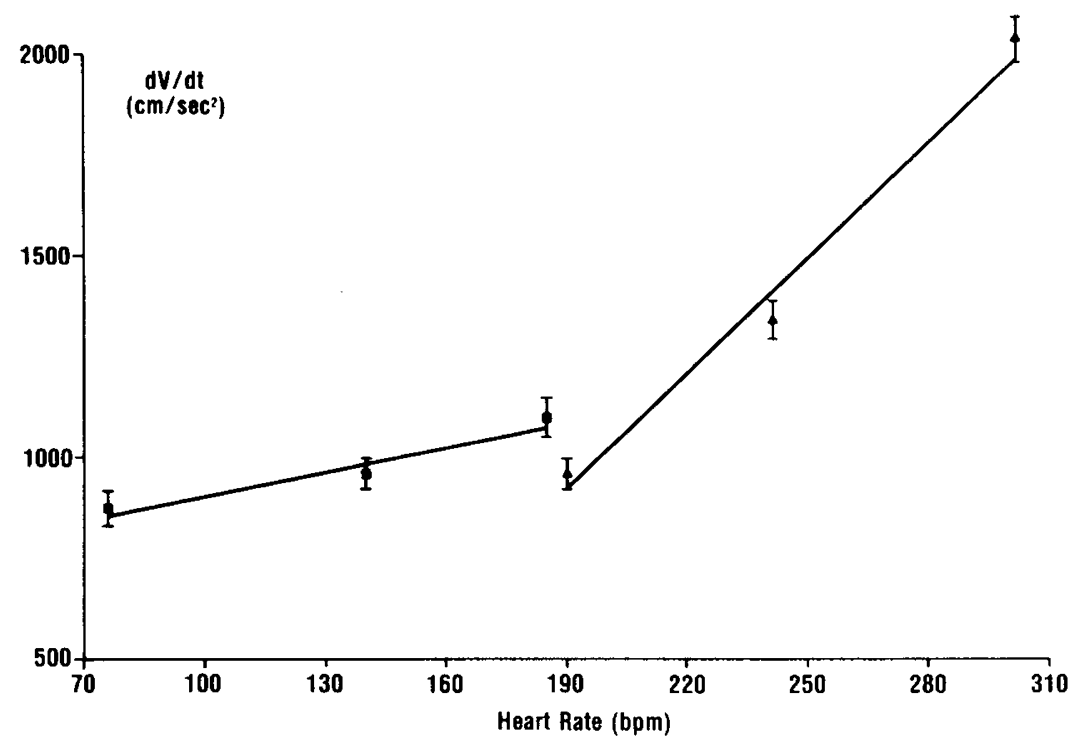

Fig. 4. The effect of pacing induced tachycardia on $\mathrm{dV} / \mathrm{dt}$. For the adults $(\mathbf{\square})$, the relationship is described by $\mathrm{y}=2.1 \mathrm{x}+700 ; r=0.97$. For the newborns $(\boldsymbol{\Lambda})$ the relationship is described by $\mathrm{y}=9.9 \mathrm{x}-957 ; r=0.96$. Values are given as mean $\pm \mathrm{S}$.E. The standard errors of the heart rates are given in Table 2 .

groups directly regarding the relative magnitude of the inotropic effect of a heart rate increase. The positive inotropic effect of atrial pacing has been demonstrated previously in adults by: (1) an increase of myocardial oxygen consumption per beat in an isovolumic adult dog preparation (4), and (2) from measurements of pre-ejection and ejection phase induces of contractility in conscious adult humans and dogs $(2,9,17-19,21,28,33)$. It is noteworthy that the $\%$ change in $\mathrm{dP} / \mathrm{dt}$ for a given heart rate increase in our adult sheep (Fig. 3) was of a similar magnitude to results obtained when preload was kept constant in conscious adult dogs $(2,19)$. Although most studies have demonstrated a $2-$ $4 \mathrm{mmHg}$ decrease of left ventricular end diastolic pressure during pacing-induced tachycardia $(2,9,19,21,28)$ there was no change in the study by Graber and associates (18) or in our study except at the most rapid heart rate in the newborn lambs (Table 2). It is possible that the unusual activation sequence initiated by left atrial pacing may have influenced the results in the newborns by producing shunting through the foramen ovale. In the unanesthetized lamb fetus, it has been demonstrated that whereas pressure is normally higher in the right atrium than the left, left atrial pacing was associated with a higher left atrial pressure throughout most of the cycle (32). If a similar mechanism occurred in the newborn lambs, this might produce left to right shunting, which could have contributed to the decrease of LVEDP that occurred at the most rapid heart rate (Table 2). The decrease in preload would only minimize the magnitude of the positive inotropic effect of tachycardia (35). In agreement with previous studies in conscious adult humans and dogs $(9,18,19,28)$ we found on change in aortic mean blood pressure during pacing-induced tachycardia (Table 2).

The mechanism of the inotropic effect of a heart rate increase has been attributed to the effect on calcium ion movements (11). 
Edman and Johannsson (11) demonstrated a close correlation between the fraction of time that the myocardium is depolarized and the maximal contractile force developed. As calcium entry occurs during depolarization and because a faster heart rate will provide a greater total time that a cell is depolarized, a heart rate increase will be associated with a greater intracellular calcium content. As calcium release is proportional to intracellular content and as contractile force is proportional to calcium release, the result would appear to be an increase of myocardial contractile force (20). Developmental changes in membrane permeability to calcium have been described (16) but their effect on the relationship between heart rate and contractility during the neonatal period remain to be determined. Although circulating catecholamines are known to have their effect on phase 2 of depolarization when calcium entry occurs (7), no change in circulating catecholamine concentration occurred during atrial pacing in conscious adult dogs (31) and propranolol does not block the heart rate related increase of contractile function in lamb fetuses or adult dogs $(19,23)$. Consequently, augmentation of calcium entry into the ventricular myocardium and the inotropic effect of tachycardia during pacing does not appear to be mediated by an increase in circulating catecholamine concentration.

Our data demonstrates that an increase in heart rate is associated with an increase of left ventricular contractile function in conscious neonatal lambs. Furthermore, no species variability was observed when we compared the results in the adult sheep with data from adult dogs (19). The slope of the regression equations for $\mathrm{dP} / \mathrm{dt}$ and $\mathrm{dV} / \mathrm{dt}$ was much greater in the newborns than in the adults (Fig. 3 and 4); however, it is not possible to determine if these differences of slope are related to differences in the range of absolute heart rate, which we studied, or that they represent an intrinsically greater inotropic effect of tachycardia in the newborns. Our study demonstrates that investigations of potential inotropic stimuli, which are also associated with a heart rate increase, must control for the independent effect of an isolated heart rate increase on contractile function.

\section{REFERENCES AND NOTES}

I. Anderson, P. A. W., Manring, A., and Crenshaw, C., Jr.: Biophysics of the developing heart. I. The force-interval relationship. Am. J. Obstet. Gynecol. 138: 33 (I980)

2. Barnes, G. E., Horwitz, L. D., and Bishop, V. S.: Reliability of the maximum derivatives of left ventricular pressure and internal diameter as indices of the inotropic state of the depressed myocardium. Cardiovasc. Res., 13: 652 (1979).

3. Berman, W., Jr. and Musselman, J.: Myocardial performance in the newborn lamb. Am. J. Physiol., 237: H66 (1979).

4. Boerth, R. C., Covell, J. W., Pool, P. E., and Ross, J., Jr.: Increased myocardial oxygen consumption and contractile state associated with increased heart rate in dogs. Circ. Res., 24: 725 (1969).

5. Bowditch, H. P.: Über die eigenthumlichkeiten der reizbarkeit, welche die muskelfasern des herzens zeigen. Arb. Physiologichen Anstalt, Leipzig, 6: 139 (1871).

6. Braunwald, E.: Heart Disease: A Textbook of Cardiovascular Medicine. pp. 472 492. (Saunders, Philadelphia, 1980)

7. Carmeliet, E. and Vereecke, J.: Adrenaline and the plateau phase of the cardiac action potential. Pflugers Arch. Eur. J. Physiol., 313: 300 (1969).

8. Davies, P., Dewar, J., Tynan, M., and Ward, R.: Postnatal changes in the lengthtension relationship of cat papillary muscles. J. Physiol. (Lond.), 253: 95 (1975).

9. DeMaria, A. N., Neumann, A., Schubart, P., Lee, G., and Mason, D. T. Systematic correlation of cardiac chamber size and ventricular performance determined with echocardiography and alterations in heart rate in normal persons. Am. J. Cardiol., 43: 1 (1979).

10. Downing, S. E., Talner, N. S., and Gardner, T. H.: Ventricular function in the newborn lamb. Am. J. Physiol., 208: 931 (1965)

11. Edman, K. A. P. and Johannsson, M.: The contractile state of the rabbit papillary muscle in relation to stimulation frequency. J. Physiol. (Lond), 254:565 (1976).

12. Falsetti, H. L., Kiser, K. M., Francis, G. P., and Belmore, E. R.: Sequential velocity development in the ascending and descending aorta in the dog. Circ. Res., 31: 328 (1972).

13. Fisher, D. J., Heymann, M. A., and Rudolph, A. M.: Myocardial consumption of oxygen and carbohydrates in newborn sheep. Pediatr. Res., 15: 843 (1981).
14. Fisher, D. J., Heymann, M. A., and Rudolph, A. M.: Myocardial oxygen and carbohydrate consumption in fetal lambs in utero and in adult sheep. Am. J. Physiol., 238: H399 (1980).

15. Friedman, W. F.: The intrinsic physiologic properties of the developing heart. Prog. Cardiovasc. Dis., 15: 87 (1972).

16. George, B. L., Nakanishi, T., and Jarmakani, J. M.: The effect of developmental changes in membrane permeability to calcium on cardiac function. Pediatr. Res., (abstract), 13: 344 (1979).

17. Glick, G., Sonnenblick, E. H., and Braunwald, E.: Myocardial force-velocity relations studied in intact unanesthetized man. J. Clin. Invest., 44: 978 (1965).

18. Graber, J. D., Conti, C. R., Lappe, D. L., and Ross, R. S.: Effect of pacinginduced tachycardia and myocardial ischemia on ventricular pressure-velocity relationships in man. Circulation, 46: 74 (1972).

19. Higgins, C. B., Vatner, S. F., Franklin, D., and Braunwald, E. Extent of regulation of the hearts contractile state in the conscious dog by alteration in the frequency of contraction. J. Clin. Invest., 52: 1187 (1973).

20. Katz, A. M.: Physiology of the heart. pp. 137-173. (Raven Press, New York 1977)

21. Karliner, J. S., Le Winter, M. M., Mahler, F., Engler, R., and O'Rourke, R. A Pharmacologic and hemodynamics influence on the rate of isovolumic left ventricular relaxation in the normal conscious dog. J. Clin. Invest., 60: 511 (1977)

22. Kirkpatrick, S. E., Pitlick, P. T., Naliboff, J., and Friedman, W. F.: FrankStarling relationship as an important determinant of fetal cardiac output. Am. J. Physiol., 231: 495 (1976).

23. Kirkpatrick, S. E., Naliboff, J., Pitlick, P. T., and Friedman, W. F.: Influence of poststimulation potentiation and heart rate on the fetal lamb heart. Am. J. Physiol., 229: 318 (1975).

24. Klopfenstein, H. S. and Rudolph, A. M.: Postnatal changes in the circulation and responses to volume loading in sheep. Circ. Res., 42: 839 (1978).

25. Koch-Weser, J. and Blinks, J. R.: The influence of the interval between beats on myocardial contractility. Pharmacol. Rev., 15: 601 (1963).

26. Lister, G., Walter, T. K., Vermold, H. T., Dallman, P. R., and Rudolph, A. M. Oxygen delivery in lambs: cardiovascular and hematologic development. Am. J. Physiol., 237: H668 (1979).

27. Mahler, F., Ross, J., Jr., O'Rourke, R. A., and Covell, J. W.: Etfects of changes in preload, afterload and inotropic state on ejection and isovolumic phase measures of contractility in the conscious dog. Am. J. Cardiol, 35:626 (1975)

28. Mahler, F., Yoran, C., and Ross, J., Jr.: Inotropic effect of tachycardia and post stimulation potentiation in the conscious dog. Am. J. Physiol., 227: 569 (1974).

29. Nichols, W. W., Pepine, C. J., Conti, C. R., Christie, L. G., and Feldman, R. L. Evaluation of a new catheter-mounted electromagnetic velocity sensor during cardiac catheterization. Catheterization Cardiovasc. Diagn., 6: 97 (1980).

30. Noble, M. I. M., Trenchard, D., and Guz, A.: Left ventricular ejection in conscious dogs: I. Measurements and significance of the maximum acceleration of blood from the left ventricle. Circ. Res., 19: 139 (1966).

31. Ohyagi, A., Sasayama, S., Tckahashi, M., Nakamura, M., Yamamoto, A., Lee, J., Yui, Y., and Kawa, C.: Effect of tachycardia induced by exercise and atrial pacing on contractile function in conscious dogs. Circulation (abstract), 64: 177 (1981).

32. Pitlick, P. T., Kirkpatrick, S. E., and Friedman, W. F.: Distribution of feta cardiac output: importance of pacemaker location. Am. J. Physiol., 231: 204 (1976).

33. Quinones, M. A., Gaasch, W. H., and Alexander, J. K. Influence of acute changes in preload, afterload, contractile state and heart rate on ejection and isovolumic indices of myocardial contractility in man. Circulation, 53: 293 (1976).

34. Riemenschneider, T. A., Brenner, R. A., and Mason, D. T.: Maturational changes in myocardial contractile state of newborn lambs. Pediatr. Res., 15: 349 (1981)

35. Ross, J., Jr.: On the assessment of cardiac inotropic state. Circulation, 47:435 (1973).

36. Rudolph, A. M.: Congenital Diseases of the Heart. (Year Book Medical Publishers, Chicago, 1974).

37. Sidi, D., Kuipers, J. R. G., Heymann, M. A., and Rudolph, A. M.: Myocardial blood flow and $\mathrm{O}_{2}$ consumption during acute hypoxemia in newborn lambs. Pediatr. Res. (abstract), 15: 472 (1971).

38. Van Den Bos, G. C., Elizinga, G., Westerhof, N., and Noble, M. I. M.: Problems in the use of indices of myocardial contractility. Cardiovasc. Res., 7: 834 (1973).

39. Wallenstein, S., Zucker, C. L., and Fleiss, J. L.: Some stastical methods useful in circulation research. Circ. Res., 47: 1 (1980).

40. Zar, J. H. Biostatistical Analysis: (Prentice-Hall, Inc., Englewood Cliff, 1974).

41. The authors gratefully acknowledge the technical assistance of Ms. Elizabeth Wiltz and the secretarial assistance of Ms. Suzanne Klein.

42. Requests for reprints should be addressed to: Dr. David J. Fisher, The University of Texas Medical School at Houston, Department of Pediatrics, P.O. Box 20708, Houston, Texas 77025 .

43. Supported by a grant from The American Heart Association, Texas Affiliate and a Biomedical Research Grant from The University of Texas

44. Received for publication June 25, 1982.

45. Accepted for publication December 7, 1982 